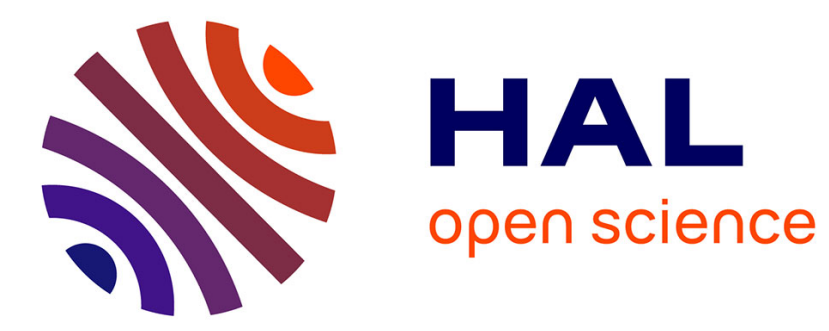

\title{
Mechanism for non stationary behaviour of thin-film superconducting bridges in the resistive current state
}

\author{
V.P. Galaiko, V.M. Dmitriev, E.V. Khristenko, G.E. Churilov
}

\section{To cite this version:}

V.P. Galaiko, V.M. Dmitriev, E.V. Khristenko, G.E. Churilov. Mechanism for non stationary behaviour of thin-film superconducting bridges in the resistive current state. Revue de Physique Appliquée, 1974, 9 (1), pp.161-163. 10.1051/rphysap:0197400901016100 . jpa-00243729

\section{HAL Id: jpa-00243729 https://hal.science/jpa-00243729}

Submitted on 1 Jan 1974

HAL is a multi-disciplinary open access archive for the deposit and dissemination of scientific research documents, whether they are published or not. The documents may come from teaching and research institutions in France or abroad, or from public or private research centers.
L'archive ouverte pluridisciplinaire HAL, est destinée au dépôt et à la diffusion de documents scientifiques de niveau recherche, publiés ou non, émanant des établissements d'enseignement et de recherche français ou étrangers, des laboratoires publics ou privés. 


\title{
MECHANISM FOR NONSTATIONARY BEHAVIOUR OF THIN-FILM SUPERCONDUCTING BRIDGES IN THE RESISTIVE CURRENT STATE
}

\author{
V. P. GALAIKO, V. M. DMITRIEV, E. V. KHRISTENKO \\ and G. E. CHURILOV \\ Physico-Technical Institute of Low Temperatures \\ Academy of Sciences of the Ukrainian SSR, Kharkov, USSR
}

\begin{abstract}
Résumé. - Des microponts Josephson courts, préparés sur une face d'un résonateur en rutile $\left(\mathrm{TiO}_{2}\right)$, présentent des courbes $I-V$ structurées en marches indiquant ainsi que des courants Josephson sont générés pour divers modes de résonance de la cavité. Des ponts très longs $(10 \mathrm{~mm})$ émettent un rayonnement dans la bande 30 à $200 \mathrm{MHz}$ quand ils se trouvent dans l'état résistif. Un modèle laminaire, où les phases normales et supraconductrices sont alternées, rend bien compte des observations expérimentales.
\end{abstract}

Abstract. - Short Josephson bridges prepared on one face of a rutile resonator show step structure in their $I-V$ curves indicating coupling of generated Josephson currents with various cavity modes. Long $(\sim 10 \mathrm{~mm})$ bridges emit radiation in the $30-200 \mathrm{MHz}$ range. The radiation occurs when the bridge is in the resistive current state. A model of a dynamic phase lamination, i. e., normal and superconducting phases alternating along the bridge, yields agreement with the experimental observations.

Among various kinds of Josephson junctions the thin-film superconducting bridges are of particular importance due both to their technological possibilities and their « difficulty » in developing the Josephson features. For instance, direct radiation was not recorded up to now although a stepped structure in $I-V$ characteristics [1] and some other manifestations of Josephson features [2] have been observed.

Our preliminary studies permit us to propose a mechanism for nonstationary behaviour of bridges. We investigated both the typical very short bridges of 1-10 $\mu \mathrm{m}$ width and 100-5 $000 \AA$ thickness and very long ones of $\sim 10 \mathrm{~mm}$ length, $30-150 \mu \mathrm{m}$ width and of a thickness in the same limits. The bridges were obtained by evaporating $\mathrm{Sn}$ in a high and pure vacuum. To record $I-V$ characteristics a four-probe technique was used.

The short Josephson bridges were deposited onto one of the faces of a rutile resonator, the dominant $\mathrm{H}$-mode having the resonance frequency

$$
f_{\mathrm{p}}=6700 \mathrm{Mcps} \text {. }
$$

The rutile resonator has been used firstly because the $\mathrm{H}$-mode structure must provide a close connection with a possible electromagnetic radiation of the bridge (Fig. 1) and secondly because its high $Q$ at helium temperatures must favour the development of even very weak oscillations. Figure 2 shows the $I-V$ curve with its typical intrinsic Josephson steps. The figure near each step shows its subharmonicity or harmonicity according to the Josephson relation [3] :

$$
n h f_{\mathrm{p}}=2 \mathrm{eVm}
$$

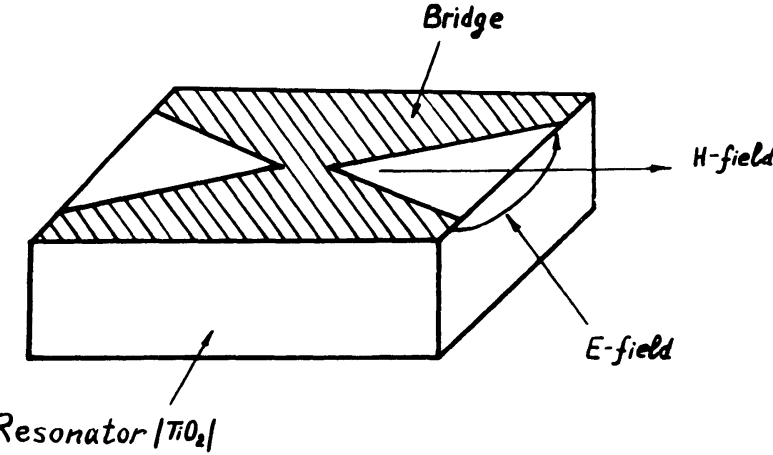

FIG. 1.

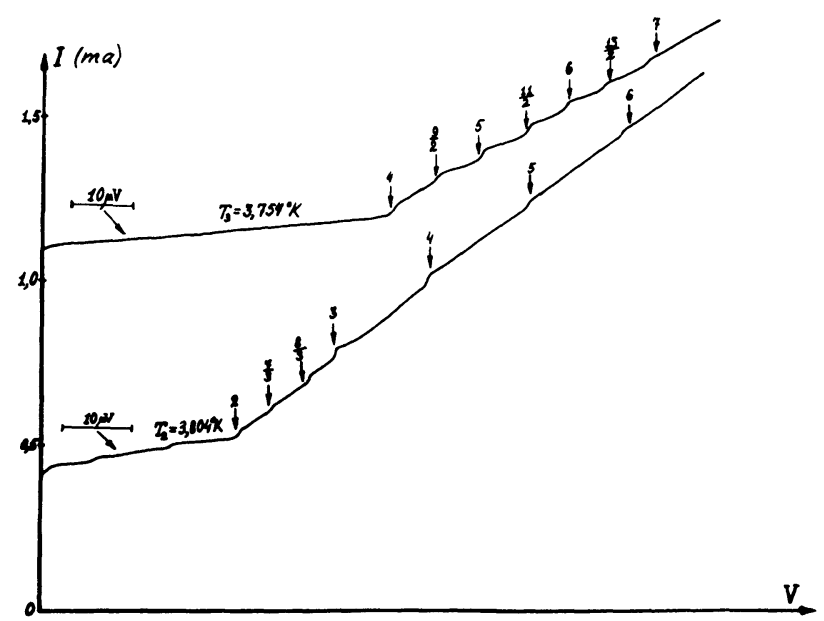

FIG. 2. 
where $n$ and $m$ are integers. For the present the generation could not be directly observed due to a weak connection between the high $Q$ rutile resonatorbridge system and the waveguide. Nevertheless we can say that the bridges have their intrinsic Josephson oscillations.

Every excitation of electromagnetic waves means a nonequilibrium distribution of electric charge and its change in time. It is especially evident for a tunnel structure which is a plane condenser with a distribution of a voltage-type charge (the voltage is given). The bridge is a conductor and therefore inductive, and one can talk, clearly, about a nonequilibrium distribution of induction-type charge (the current is given). The situation is non-trivial and, as the microscopic calculation shows, is of principal importance for calculating the instability of the normal current state to the appearance of superconducting nuclei.

In this connection $I-V$ curves for long bridges and associated electromagnetic energy radiation [4] have been thoroughly investigated. These bridges were incorporated in a retuning circuit and the amplitude and frequency of the generated oscillations as well as the $I-V$ curves were recorded simultaneously at different temperatures. Much prominence was given to the fact that the critical current for such bridges, $j_{\mathrm{c}}$, corresponded both to the value and temperature dependence calculated by the Ginzburg-Landau theory [5].

As a result we have the following :

1. For different temperatures the given frequency is generated at the same reduced current $j_{\mathrm{g}} / j_{\mathrm{c}}$ since the temperature dependence of $j_{\mathrm{g}}$ coincides with that of $j_{\mathrm{c}}$ [5] (Fig. 3). Here $t=T / T_{\mathrm{c}}$ where $T_{\mathrm{c}}$ is the critical temperature.

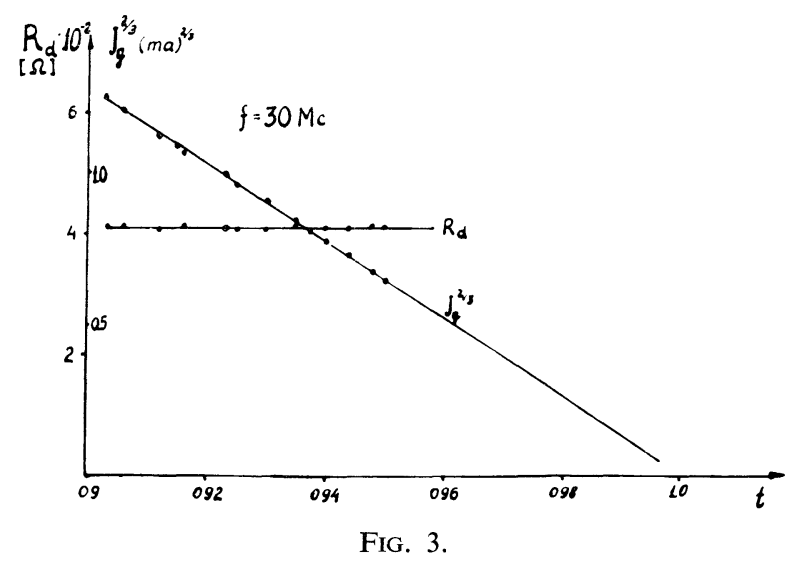

2. The bridge differential resistance $R_{\mathrm{d}}=\mathrm{d} U / \mathrm{d} j$ at a generation point in a $I-V$ curve remains constant for a fixed frequency with temperature change (Fig. 3), the constancy of $R_{\mathrm{d}}$ occurring when the law of corresponding current states is fulfilled.

3. Higher generation frequencies correspond to higher values of $R_{\mathrm{d}}$ in $I-V$ characteristics at a fixed temperature (Fig. 4).

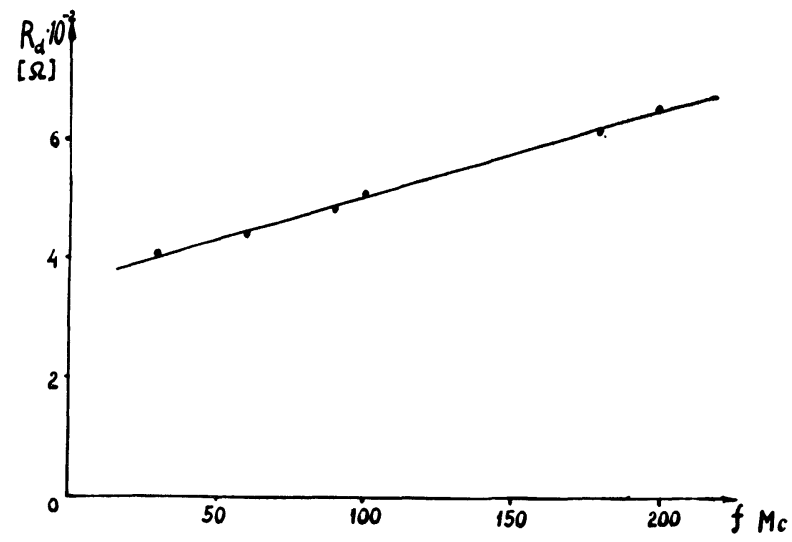

FIG. 4.

It is evident that the observed generation and $I-V$ characteristic peculiar features are in close connection with the nature of resistive current states in superconductors of small transverse dimensions. Note also that both for short and long bridges the nonstationary behaviour is developed in the region of the resistive state, i. e., when the constant electric field $E$ exists in the film. Neither Abrikosov vortex structure [6], [7], nor an intermediate state structure with current [8] nor taking a fluctuation current $\left({ }^{1}\right)$ into account [9], [10] can explain the resistivity of superconductors with small transverse section; the only possible explanation assumes a dynamic phase lamination, i. e., normal and superconducting regions alternating along the bridge (Fig. 5). Such a lamination must develop from

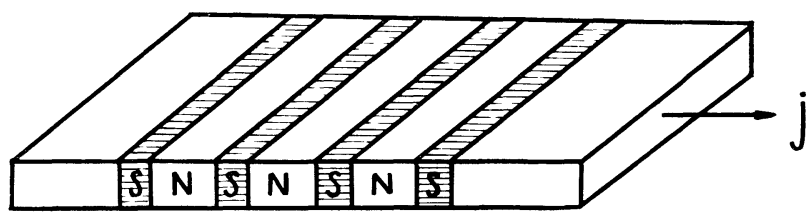

FIG. 5.

the normal current state as the current decreases below some critical value $j_{\mathrm{c}_{2}}$; this occurs as a result of the development of Cooper instability and is similar to the appearance of the mixed state in type II superconductors at fields smaller than $H_{\mathrm{c}_{2}}$ [6]. In view of the resistive state nonequilibricity the resulting structure is assumed to be dynamic; it is this dynamic nature that should result in the generation of electromagnetic waves. The picture described is in qualitative agreement with the experimental results since a specific structure, and therefore a specific radiation frequency, corresponds to the current state of a specific $R_{\mathrm{d}}$.

It should be noted that under the transition to the mixed state the superconducting nuclei result from

(1) As the estimates show, for electric fields corresponding to the resistive part of the $I-V$ curve the fluctuation current is extremely small. 
the thermodynamically equilibrium normal state, and in the above situation instability arises from the dissipative normal current state while passing through the critical current $j_{\mathbf{c}_{2}}$.

This means that this instability cannot be described by the so-called time-dependent Ginzburg-Landau equation [11] since the latter describes the timedependent behaviour of the superconducting order parameter in the vicinity of the equilibrium normal state.

The microscopic calculation of the instability mentioned was carried out on the basis of kinetic equations for the generalized electron-hole matrix of the density of the superconductor which are suggested in [12], [13]. The results are to be published. Here are presented the results of the calculation for the critical current $j_{\mathrm{c}_{2}}$, found experimentally from the $I-V$ curve point where the deviation from the Ohmic law starts in the normal state of the current

$$
j_{\mathrm{c}_{2}}=\sigma_{\mathrm{n}} E_{\mathrm{c}_{2}}, \quad E_{\mathrm{c}_{2}}=\frac{4 k\left(T_{\mathrm{c}}-T\right)}{\mathrm{e}} \sqrt{\frac{2 \pi k T_{\mathrm{c}}}{7 . \zeta(3) \cdot \hbar \cdot \mathscr{D}}},
$$

where $\sigma_{\mathrm{n}}=\frac{N \mathrm{e}^{2} \tau}{m}$ is the normal conductivity of the film, $k$ the Boltzmann constant, $\zeta(3)$ the special value of the Riemann $\zeta$-function

$$
\mathcal{D}=\frac{8 V_{\mathrm{F}}^{2}}{3 \pi^{2}} \sum_{n=0}^{\infty} \frac{1}{(2 n+1)^{2}}\left[2 \pi T_{\mathrm{c}}(2 n+1)+\frac{1}{\tau}\right]^{-1}
$$

and $V_{\mathrm{F}}$ the Fermi velocity.

The physical explanation of the result obtained is simple. The instability appears when the energy gained by an electron in the electric field at the coherence length $\xi(T)$ is of the order of magnitude of the condensation energy $\Delta(T)$ or smaller

$$
(\mathrm{e} E \xi(T) \leqslant \Delta(T)) .
$$

We have already mentioned the formal analogy of the transition to the state described with that to the mixed state. Now we point to the relation between $E_{\mathrm{c}_{2}}$ and $H_{\mathrm{c}_{2}}$ which has the form $\left({ }^{2}\right)$

$$
E_{\mathrm{c}_{2}}=\pi H_{\mathrm{c}_{2}} \sqrt{\frac{2 \pi \mathfrak{D} \cdot T_{\mathrm{c}}}{7 . \zeta(3)}}
$$

(2) This, by the way, suggests a new possibility for finding $H_{\mathrm{c}_{2}}$ since $E_{\mathrm{c}_{2}}$ is readily found from $I-V$ curve.
The current region between $j_{\mathrm{c}}$ and $j_{\mathrm{c}_{2}}>j_{\mathrm{c}}$ is the region of the resistive current state characterized by dynamic phase lamination. The latter is responsible for generating electromagnetic energy. Its description is to be given. We shall note that the experimentally observed temperature dependence for $E_{\mathrm{c}_{2}}$ is, as seen from figure 6 , linear, and its order of magnitude is in good agreement with the calculation.

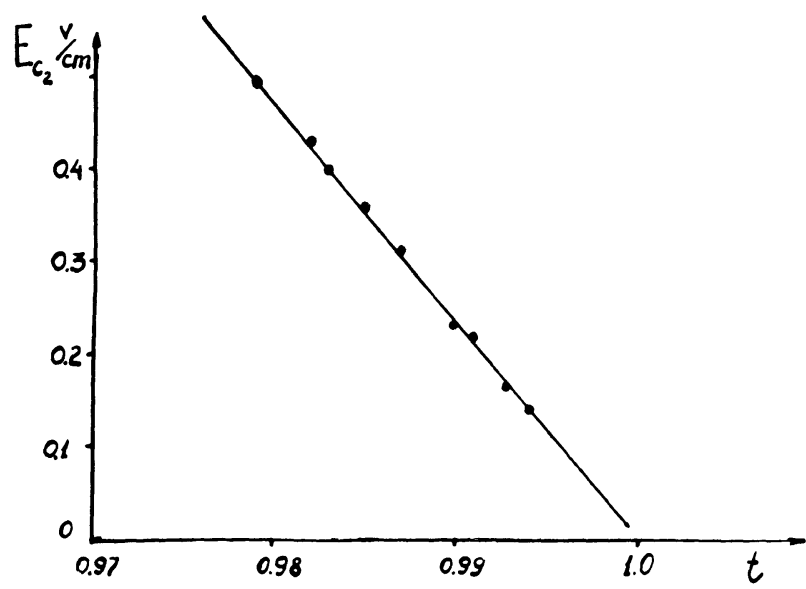

FIG. 6.

Thus, we may conclude that particular conditions may create different situations in bridges which cause either Josephson (concentrated) or non-Josephson (distributed) oscillations, just as in klystrons and travelling-wave tubes, respectively. In this sense detailed studies of bridges would assist in understanding the physical difference and similarity and perhaps interrelation between both these mechanisms of generation.

From the practical viewpoint, the «distributed » oscillations seem to be promising enough in achieving high power (at sufficiently low temperatures the equivalent power in the resistive portion of the $I-V$ curve easily reaches tens and hundreds of milliwatts) and supplying the power to the transmission line (in fact it is the problem of matching for the post and waveguide). This provides a simple current retuning of the generator. In this case the wide bandwidth is determined by the possible $I-V$ range of dynamic resistances. Though much work is to be done to obtain meaningful results.

\section{References}

[1] Dayem, A. H., Wiegand, J. J., Phys. Rev. 155 (1967) 2, 419.

[2] Notarys, H. A., Mercereau, J. E., Physica 55 (1971) 2, 424-431.

Gregers-Hansen, P. E., Levinsen, M. T., Pedersen, L. and Suostrøm, C. J., Solid State Commun. 9 (1971) 661-664.

[3] Anderson, P. W., Progress in Low Temperature Physics 5 (1967).

[4] Churilov, G. E., Dmitriev, V. M., Beskorsy, A. P., Pisma v JETF 10 (1969) 231.

[5] Ginzburg, V. L., Landau, L. D., JetF 20 (1950) 1064.
[6] Abrikosov, A. A., JETF 32 (1957) 1442.

[7] Kim, Y. B., Hempstead, C. F., Strnad, A. R., Phys. Rev. 139 (1965) A 1163.

[8] Andreev, A. F., Pisma v JETF 6 (1967) 836

[9] Gorkov, L. P., Pisma v JETF 11 (1970) 52.

[10] KuLIK, I. O., JETF 59 (1970) 584.

[11] Abrahams, E., Tsuneto, T., Phys. Rev. 152 (1966) 416.

[12] Galaiko, V. P., JETF 61 (1971) 382.

[13] Galaiko, V. P., Fizika kondensirovannogo sostoyania, vyp. XIV, FTINT AN Ukr. SSR, 1971. 